Article

\title{
Cyclic Voltammetric and Quantum Chemical Studies of a Poly(methionine) Modified Carbon Paste Electrode for Simultaneous Detection of Dopamine and Uric Acid
}

\author{
Bananakere Nanjegowda Chandrashekar ${ }^{1,2}$, Weizhong Lv $^{3, *}$, Gururaj Kudur Jayaprakash ${ }^{4,5}(\mathbb{D}$, \\ Karim Harrath ${ }^{6}$, Louis W.Y. Liu ${ }^{7,8, *(1)}$ and Bahaddurghatta E. Kumara Swamy ${ }^{9, *}$ \\ 1 Laboratory of Advanced Materials Chemistry, Advanced Institute of Materials Science, Ton Duc Thang \\ University, Ho Chi Minh City, Vietnam; chandrashekar@tdtu.edu.vn \\ 2 Faculty of Applied Sciences, Ton Duc Thang University, Ho Chi Minh City, Vietnam \\ 3 College of Chemistry and Environmental Engineering, Shenzhen University, Shenzhen 518060, China \\ 4 Departamento de Ingeniería de Proyectos, Centro Universitario de Ciencias Exactas e Ingenierías, Blvd. \\ Marcelino García Barragán 1421, Guadalajara Jal. C.P. 44430, México; rajguru97@gmail.com \\ 5 Department of Chemistry, Tsinghua University, Beijing 100084, China \\ 6 Faculty of sciences of Tunis, El Manar University, Tunis 2092, Tunisia; karimharath2011@hotmail.fr \\ 7 Faculty of Electrical and Electronics Engineering, Vietnamese-German University, Le Lai Street, Hoa Phu \\ Ward, Thu Dau Mot City, Vietnam \\ 8 Faculty of Electrical and Electronics Engineering, Ton Duc Thang University, 19 Nguyen Huu Tho, Ho Chi \\ Minh City, Vietnam \\ 9 Department of P.G. Studies and Research in Industrial Chemistry, Kuvempu University, Shankaraghatta, \\ Shimoga, Karnataka 577451, India \\ * Correspondence: lvwzh@szu.edu.cn (W.L.); liu.waiyip@vgu.edu.vn (L.W.Y.L.); \\ bek@kuvempu.ac.in (B.E.K.S.)
}

Received: 26 March 2019; Accepted: 2 May 2019; Published: 7 May 2019

check for updates

\begin{abstract}
Fabrication of biocompatible electrodes for the investigation of catecholamines is a known challenge. In this work, methionine was chosen as a modifier for fabrication of a biocompatible carbon paste electrode by electropolymerization, through cyclic voltammetry. The electrochemical behavior of the poly(methionine) modified carbon paste electrode was characterized by cyclic voltammetry for simultaneous determination of dopamine (DA) and uric acid (UA) in a phosphate-buffered solution at $\mathrm{pH}$ 7.0. In the absence of an amino acid methionine layer, the bare carbon paste electrode exhibits rather poor voltammetric signals in DA and UA in the binary mixture, with oxidation potentials of DA and UA overlapping with each other. The poly(methionine) modified carbon paste electrode exhibits good catalytic activity with noticeably different oxidation potentials of DA and UA. The experimental results closely agree with the theoretical prediction based on a Fukui function complementary to the simulated electrostatic potential maps.
\end{abstract}

Keywords: poly(methionine); dopamine; cyclic voltammetry; fukui functions; electrostatic potential 


\section{Introduction}

Neurotransmitters are the chemical messengers that transmit a message from one neuron to another [1]. Dopamine (DA), one of the most significant catecholamine neurotransmitters belonging to the family of excitatory chemical neurotransmitters [1-3], plays an important role in the proper functioning of the renal, central nervous, hormonal, and cardiovascular system [4]. A shortage of DA in the brain is linked to aggregation of symptoms of Parkinson's disease and other seemingly unrelated diseases, including schizophrenia and Huntington's disease, as well as drug addiction and human immunodeficiency virus (HIV) infection [1,5-8]. On the other hand, the primary end product of purine metabolism, uric acid (UA), is an important antioxidant, which protects dopaminergic neurons against oxidative damage. A shortage of UA is linked to symptoms of several diseases, such as gout, hyperuricemia, and Lesch-Nyhan disease [7-10]. In recent years, many studies have been devoted to the fabrication of chemically modified electrodes for simultaneous determination of levels of DA and UA in a binary mixture [11,12], with improving selectivity and sensitivity being one of the main objectives of electroanalytical research [11,12].

Polymer modified carbon paste electrodes (PMCPEs) prepared by electropolymerization methods are believed to be a promising candidate for detection of neurotransmitters in UA. The selectivity and sensitivity of electropolymer modified carbon electrodes are high. The electropolymers form a homogeneous deposition with strong adherence at carbon paste electrodes $[13,14]$. Electropolymers formed using essential amino acids have unique advantages over their counterparts in terms of biocompatibility. Several research groups have previously fabricated electrodes modified with a carbon coating and with essential amino acids for sensing applications. The essential amino acids that have been explored include phenylalanine [15], glycine [16], threonine [17], tryptophan [18], methionine [19], leucine [20], isoleucine [21], lysine [22], and histidine [23]. Interestingly, essential amino-acid-modified electrodes have reportedly displayed above-average sensing capabilities.

Several research groups have reported the benefits of poly(methionine) on glassy carbon electrode (GCE) materials for sensing catecholamies, and other chemicals of clinical interest [24,25]. Electrodes formed with methionine modified carbon paste have been successfully used in the determination of ascorbic acid present in natural fruits, in the real applications [26]. The use of a glassy carbon electrode modified with methionine and graphene in the determination of tryptophan in milk has been reported [27]. Furthermore, glassy carbon electrodes with poly(methionine) showed benefits in the simultaneous determination of pyrazinamide and amlodipine in urine and blood plasma [28,29]. A methionine-modified electrode was found to exhibit an excellent catalytic property towards the determination of amlodipine in human biological fluids. The benefits of electrodes chemically modified with methionine in improving their sensing capabilities have generated a lot of research interest, and, without any exception, the biocompatibility of methionine warrants further studies. In the present work, the mechanism of the poly(methionine) modified carbon paste electrode in the simultaneous determination of DA and UA is analytically and experimentally explored. Previous studies have demonstrated that layers of the amino acids coating the surface of a carbon electrode act like an electron transfer mediator, which increases the sensing abilities of the electrode [28]. Previously, the density functional theory (DFT)-based quantum chemical model has been used to explain the mediating behaviors of modifiers [2,22,29-32].

In the present investigation, conceptual DFT methods based on analytical Fukui functions and electrostatic potential maps are advantageously used for prediction of the redox reactive sites of methionine. In this work, the poly(methionine) modified carbon paste electrode (PMCPE) has been successfully used as a new sensor, which simultaneously determines levels of DA and UA in a binary mixture with no loss of selectivity and sensitivity. The detection mechanism involves elimination of the fouling effect of the oxidized products of UA due to the presence of DA. An analytical Fukui function and electrostatic potential maps are found to be highly instrumental in locating the redox electron transfer sites of the methionine molecule. Unlike other fabric materials, the carbon in the proposed PMCPE can be used as the filler material for a needle or microneedle to realize minimally invasive 
measurement of the plasma concentration of uric acid and dopamine. The biocompatible nature of the proposed PMCPE permits in-vivo diagnosis of complications of Parkinson's disease and other illnesses associated with the serum levels of uric acid. The experimental results of this work, together with the novel prediction methodology using a Fukui function and electrostatic potential maps, lay a foundation for future work in nanoelectronics and diagnostic technologies.

\section{Materials and Methods}

\subsection{Chemicals}

Dopamine $(>98 \%)$ and uric acid $(>99 \%)$ were purchased from Himidia chemicals. The stock solution of DA was prepared by dissolution in $0.1 \mathrm{M}$ perchloric acid, and UA in $0.1 \mathrm{M}$ sodium hydroxide solution, in double-distilled water. All chemicals were of analytical grade and were used without further purification. The phosphate-buffered solution (PBS) was prepared by the standard method. The experiments were performed at room temperature.

\subsection{Apparatus and Procedure}

The electrochemical experiments were carried out in a conventional three-electrode system based on a Model CHI-660c Electrochemical workstation. The three-electrode system contained a working carbon paste electrode (CPE) packed in a home-made cavity of $3 \mathrm{~mm}$ in diameter. Additionally, a platinum wire was used as a counter electrode and a saturated calomel electrode was used as a reference electrode. To prepare the bare carbon paste electrode (BCPE), 70\% of finely grinded graphite powder and $30 \%$ of silicon oil were hand-mixed in an agate mortar to obtain a homogenous mixture. The semi-solid paste was then transferred and packed into the cavity of the CPE, then air-cured and smoothened on a piece of weighing paper.

\subsection{Computational Methods and Model}

Atomic coordinates for all models were constructed using MOLDEN [33] software (Gijs Schaftenaar, CMBI, Netherlands) Full geometry optimization and electrostatic potential computations of the models were carried out using density functional theory (DFT) in the Gaussian09 program [34] with a hybrid method B3LYP $[35,36]$ for calculating exchange-correlation potential functions and 6-311G (d, p) $[37,38]$ basis sets that specify the first-row atoms and the McLean-Chandler $(12 s, 9 p) \rightarrow(621111,52111)$ basis sets for second-row atoms. We have used deMon2k [39] for the frontier molecular orbital (FMO) and Fukui functions computations. The FMO and Fukui results were finally plotted using Sinapsis [40] software (which is a public domain free software downloadable from sourceforge.net).

\section{Results}

\subsection{Electrochemical Modification of Poly(methionine) on the CPE}

Figure 1 shows that the poly(methionine) modification has been successfully achieved with $1 \times 10^{-3} \mathrm{M} \mathrm{L}^{-1}$ methionine in $0.1 \mathrm{M}$ PBS. In the first potential sweep, an oxidation peak was observed by repeated cyclic scanning of potential when the anodic peak potential reaches $-0.10 \mathrm{~V}$. During each of the following cycles, the peak was shifted to the positive potential with an increase in current, which corresponds to the time when the poly(methionine) film was formed on the CPE. The results of our experimental investigation suggest that the PMCPE film in the $0.1 \mathrm{M}$ PBS solution is relatively stable. By repeated cyclic scanning of electrode potential from -0.2 to $0.8 \mathrm{~V}$, the peak height and peak potential of the surface of the immobilized film was found to be almost constant. 


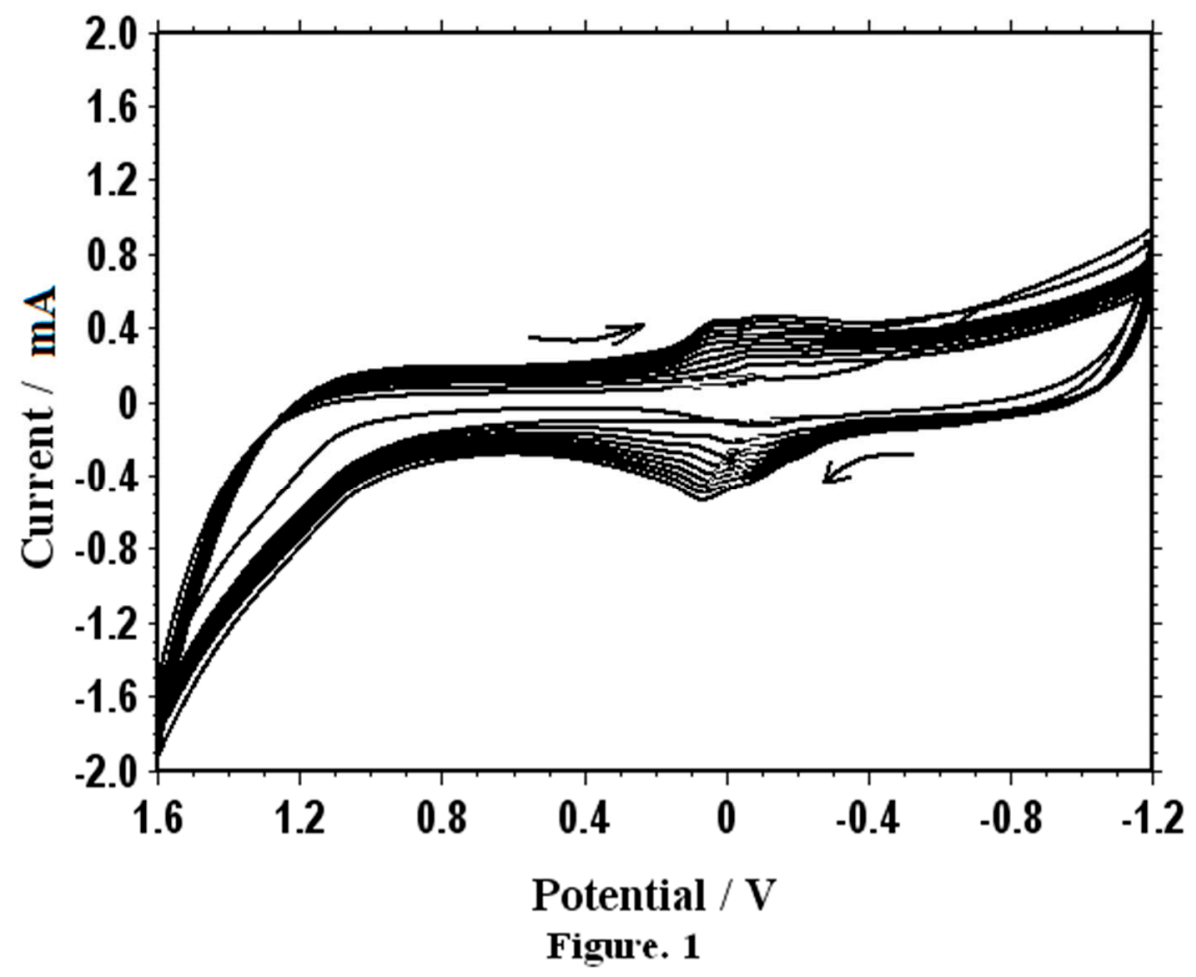

Figure 1. Cyclic voltammograms for electrochemical polymerization of methionine on a bare carbon paste electrode (BCPE) in $0.1 \mathrm{M}$ phosphate-buffered saline (PBS) $\mathrm{pH} 7.0$ by 20 segments. Sweep rate: $100 \mathrm{mV} \cdot \mathrm{s}^{-1}$.

\subsection{Electrochemical Oxidation of Dopamine}

The results of our experiment suggest that, with a PMCPE, the presence of dopamine (DA) can be easily detected with high sensitivity. As illustrated in Figure 2, the PMCPE has yielded the clearly distinguishable cyclic voltammograms for detecting the presence or absence of DA. When the bare $\mathrm{CPE}$ was used instead, however, the voltammograms for detecting the presence or absence of DA have almost merged with each other with dimly readable peaks. 


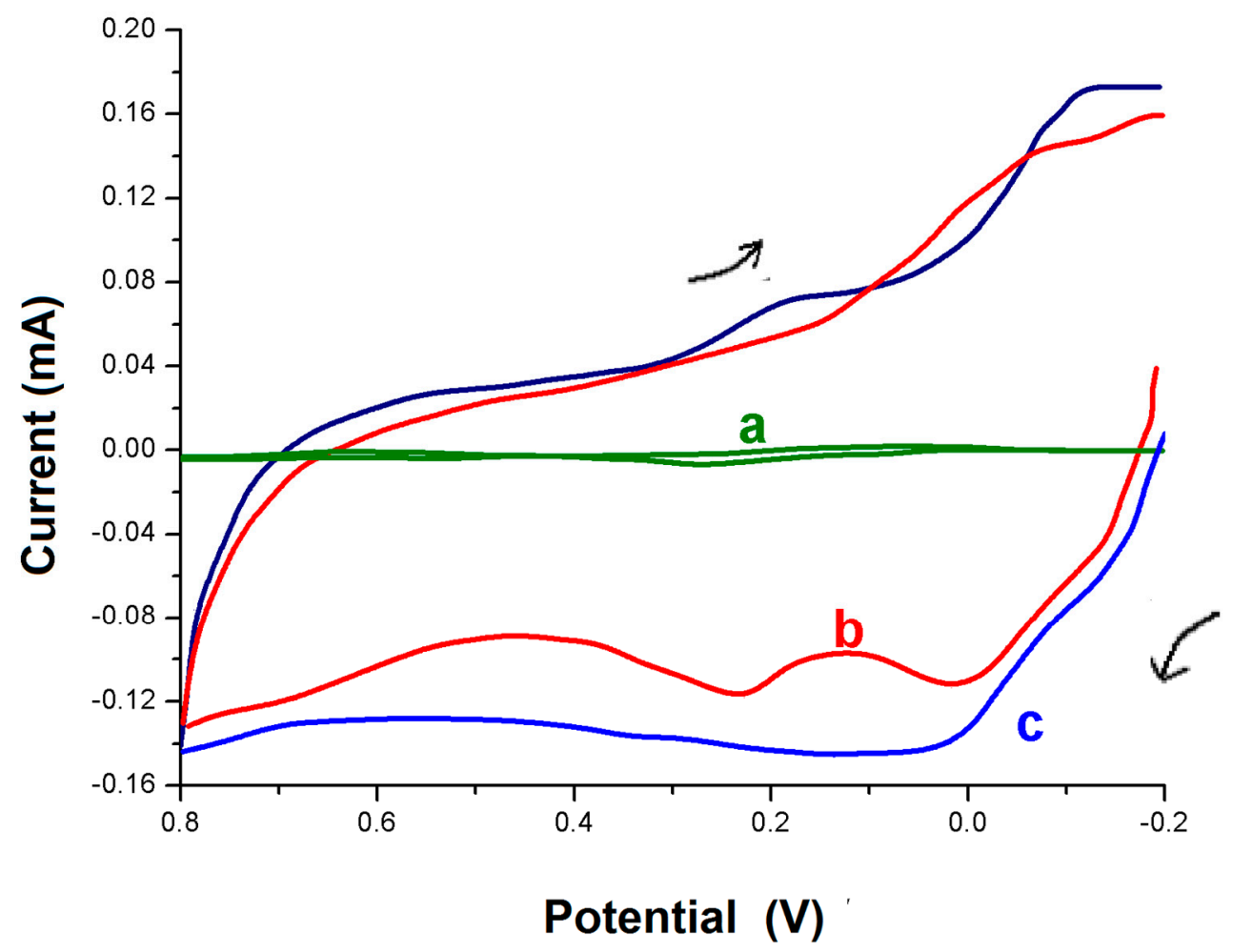

Figure 2. Cyclic voltammograms at a BCPE for detection of DA (a) and a polymer modified carbon paste electrode (PMCPE) $(\mathbf{b}, \mathbf{c})$ in the presence of $1 \times 10^{-3} \mathrm{M}$ dopamine (DA) (b) and in the absence of DA (c) in $0.1 \mathrm{M}$ PBS (pH 7.0). Scan rate: $100 \mathrm{mV} \cdot \mathrm{s}^{-1}$.

Before the experiment, the bare and modified CPE in this work have been characterized by cyclic voltammetry $(\mathrm{CV})$ using a ferro redox probe. With the $\mathrm{BCPE}$, the redox peak potential difference was $\triangle \mathrm{Ep}=90 \mathrm{mV}$. However, with the PMCPE, the peak current has increased significantly and the peak potential shifted slightly in a positive direction with a peak potential difference of $58 \mathrm{mV}$. At $\mathrm{pH} 7.0$, DA exists as a cation with a positively charged amino group. DA has exhibited a quasi-reversible response at the BCPE. With the PMCPE, however, DA has exhibited a highly noticeable reversible response. The improved sensitivity and selectivity of detection of DA observed in the PMCPE was due to an electrostatic and hydrophobic interaction between polymethionine and DA. The voltammogram $\mathrm{c}$ in Figure 3 shows the blank response of the PMCPE at 0.1 M PBS (pH 7.0). With the PMCPE, DA has exhibited a single oxidation and reduction peak, followed by another oxidation and reduction peak due to the redox reactions of methionine.

The cyclic voltammograms of DA at different scan rates are shown in Figure 3a. The plot of scan rate versus current is shown in Figure 3b, from which it can be seen that, as the scan rate increases, the current also increases. The redox current intensities have increased with an increasing scan rate with a correlation coefficient $\mathrm{r}^{2}=0.9995$, suggesting that the electrode reaction was adsorption-controlled. According to Figure $3 b$, the current can be linearly regressed in terms of the scan rates, using the following equation: $\mathrm{I}=0.0144 \mathrm{v}+0.4$, where $\mathrm{I}$ is the current in $\mu \mathrm{A}$ and $\mathrm{v}$ is the scan rate in $\mathrm{mV} \cdot \mathrm{s}^{-1}$. 


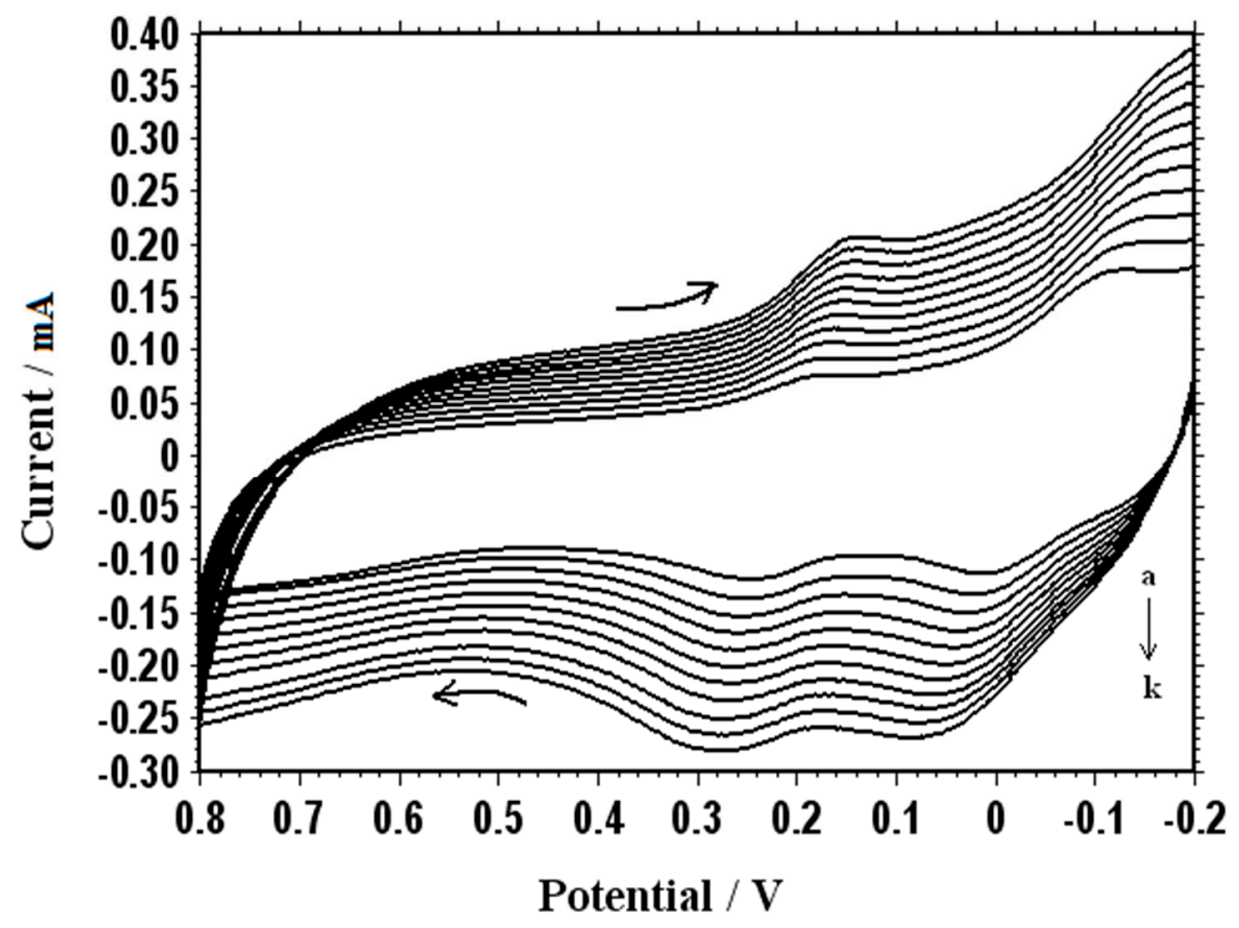

(a)

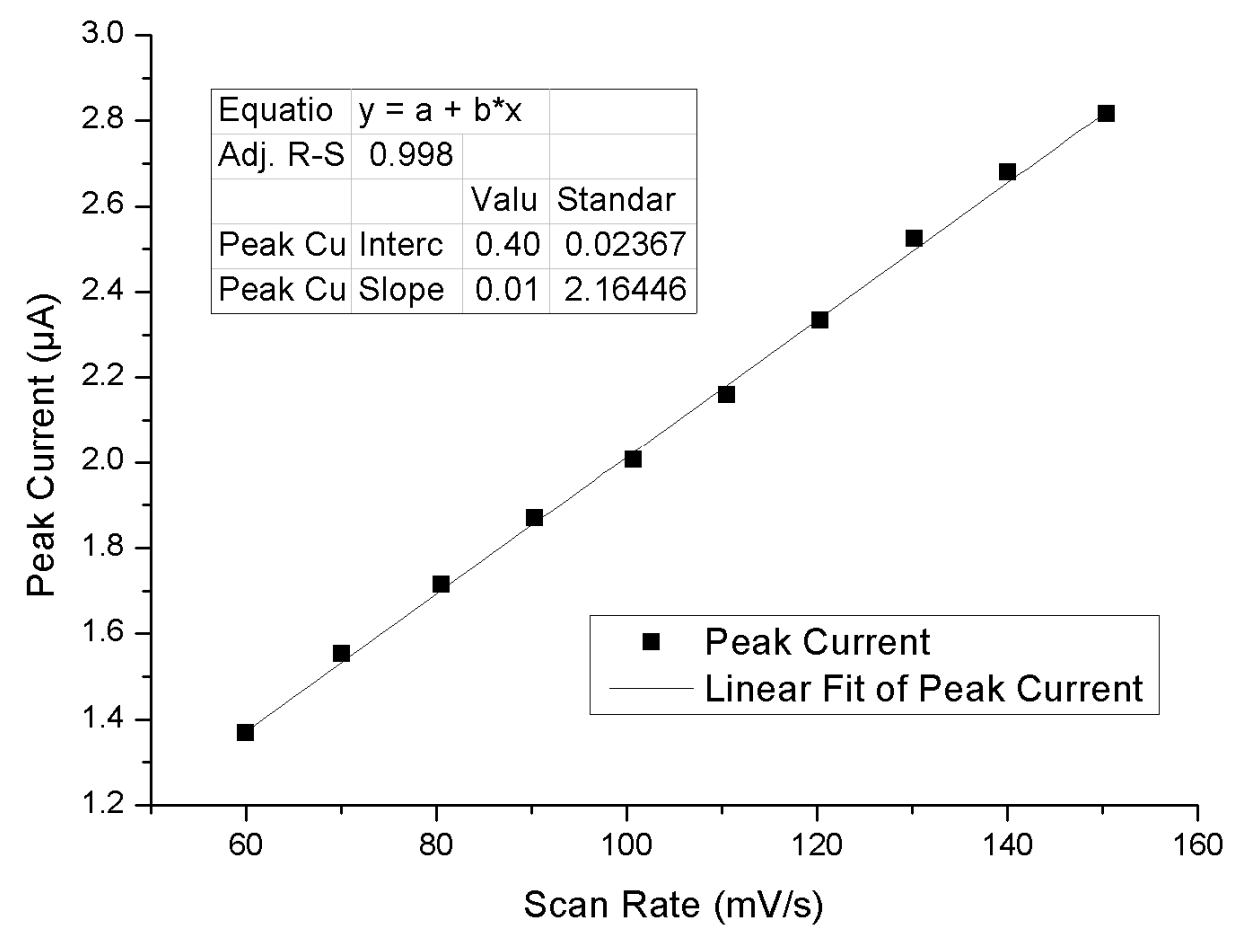

(b)

Figure 3. Cont. 


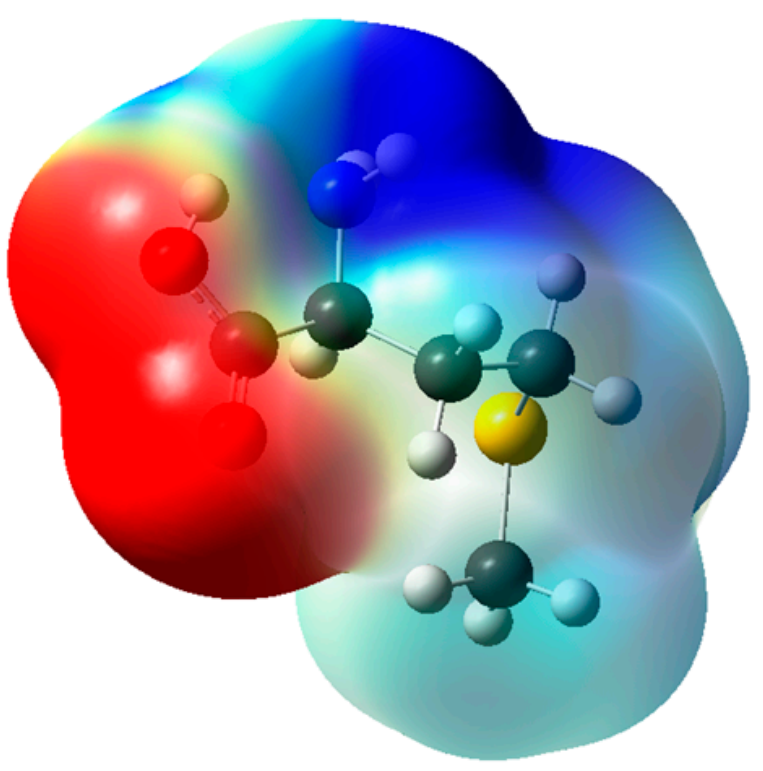

(c)

Figure 3. Effect of different scan rates: (a) Cyclic voltammograms of $1 \times 10^{-3} \mathrm{M}$ DA at different scan rates (a-k; 50, 100, 150, 200, 250, 300, 350, $400 \mathrm{mV} \cdot \mathrm{s}^{-1}$ ) in $0.1 \mathrm{M}$ PBS (pH 7.0); (b) Effect of different scan rates on the oxidation peak current of $1 \times 10^{-3} \mathrm{M}$ DA at the PMCPE. (c) An electrostatic potential map of methionine.

\subsection{Theoretical Studies of Methionine}

Methionine polymer adhered to the surface of an electrode increases the electrocatalytic activities of the PMCPE towards DA. We have previously reported several polymer modified carbon paste electrodes for the sensitive detection of DA. Based on our previous findings, we have come to the conclusion that there exists a mediated electron transfer at the PMCPE [22]. By the same token, a similar mediated electron transfer from the methionine is believed to have occurred on the surface of the PMCPE in this work. Methionine reacts with carbon to form a electropolymer on the surface of the carbon electrode, which may be the dimer or trimer or polymer. For the purpose of mathematical modeling, only a monomer of methionine is considered in the present presentation. In an attempt to determine which atoms of the methionine are involved in the redox electron transfer reactions, we have simulated the electrostatic surface potential and FMO using the Fukui concept to determine the redox electron transfer sites. As a result of this simulation, electrostatic potential energy maps showing the three-dimensional charge distribution of molecules were obtained. These maps allow us to visualize the charged regions of the methionine molecule. Knowledge of the charge distributions can be used to determine how the molecules interact with one another [29,39-41]. Figure $3 \mathrm{c}$ is one of the electrostatic potential energy maps that show the electron distributions obtained using the Gaussian09 program. It can be observed from Figure $3 \mathrm{c}$ that a high probability of electron distribution was found on the amino group and the sulfur atom, which corresponds to the reduction sites for the DA molecule. The probability of electron distribution is relatively low in the carboxylic acid group, suggesting that the carboxylic acid group is the oxidation site for DA molecules. It can be observed from Figure 4 that the highest occupied molecular orbital (HOMO) of methionine is located on the sulfur atom, and the lowest occupied molecular orbital (LUMO) is located on the carbon and oxygen atoms of the carboxylic acid group of the methionine. The results of this analysis suggest that oxidation of PMCPE occurs via the sulfur atom in the methionine molecule whilst reduction occurs through the carboxylic acid group of the molecule. 


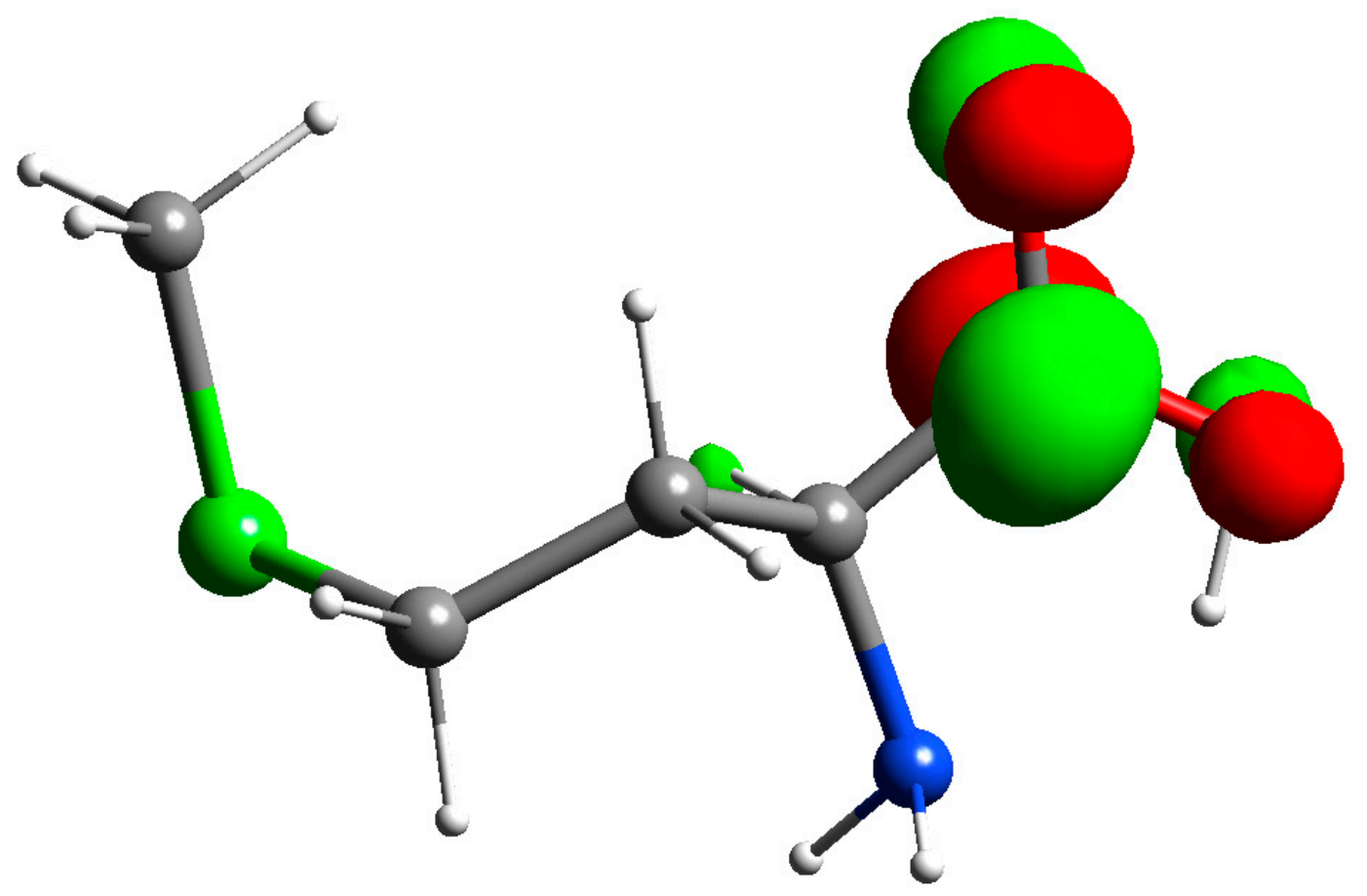

(a)

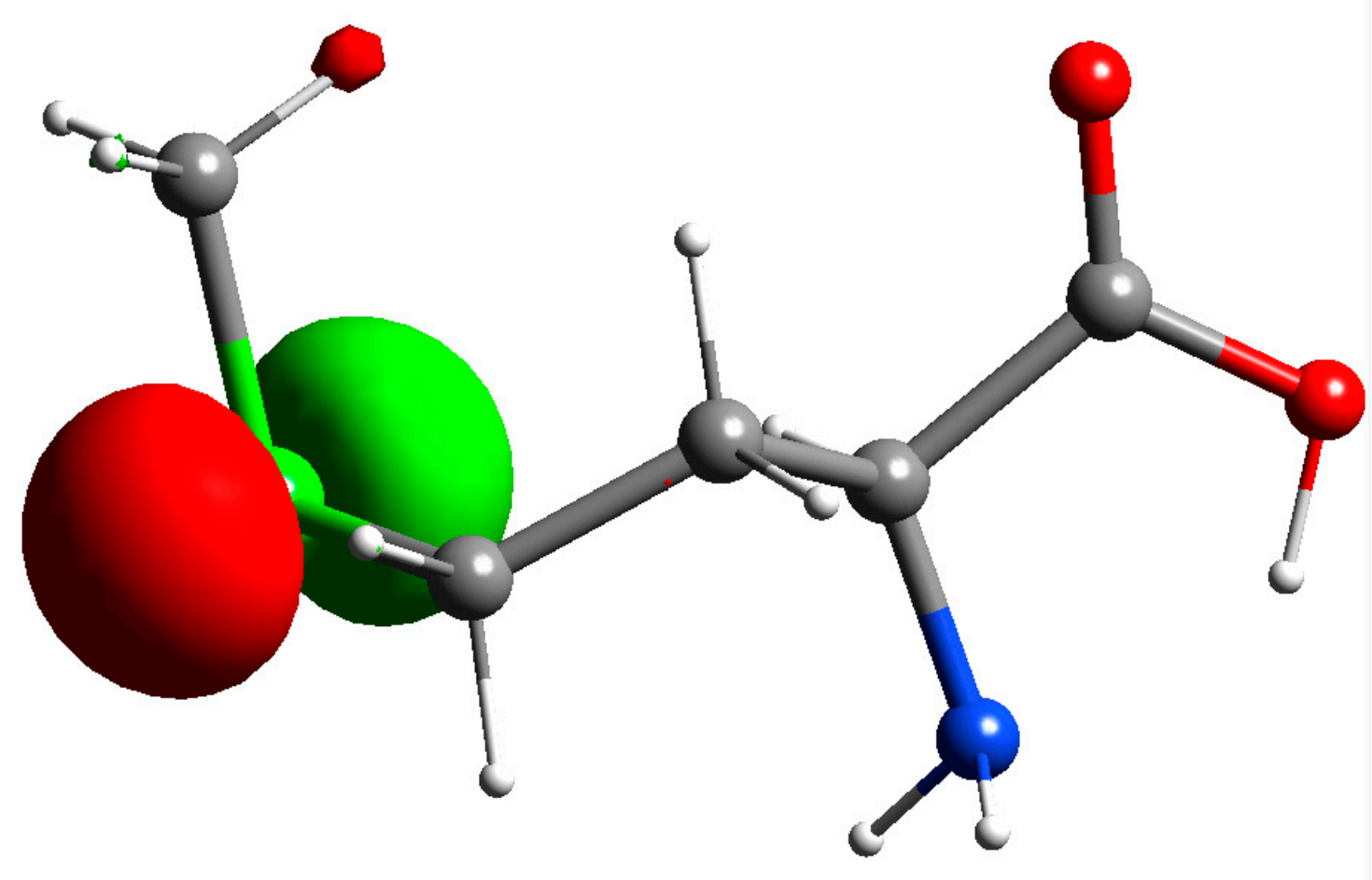

(b)

Figure 4. Orbital of methionine: (a) Lowest occupied molecular orbital (LUMO) of methionine (isosurface value of 0.09); (b) Highest occupied molecular orbital (HOMO) of methionine (isosurface value of 0.09). 
The Fukui function is generally used to understand redox reaction mechanisms in electrochemistry $[2,31]$. Simulation based on the Fukui function can be applied in chemical and electrochemical applications for locating electron transfer sites [5,28,36-38]. The Fukui function can be defined according to Equation (1) [42-45].

$$
f(r)=\left[\frac{\partial \rho(r)}{\partial N}\right]_{v(r)}^{+/-}
$$

where $\rho(r)$ is the electron density, $N$ is the number of electrons in the system, and the + and - signs correspond to addition of electrons or removal of electrons, respectively.

In this work, simulation using the Fukui function was done in deMon2k, which further reinforces the hypothesis that HOMO of methionine is located on the sulfur atom, and LUMO is located on the carbon and oxygen atoms of the carboxylic acid group of the methionine molecules. The results of simulation using the Fukui equation, as shown in Figure 5, consistently suggest that the oxidation site of the methionine is indeed located at the sulfur atom and reduction sites of the methionine are located on the carboxylic acid group. In other words, the sulfur atom of the methionine is responsible for the oxidation of PMCPE, whilst the carboxylic acid group is responsible for the reduction of PMCPE. The electron transfer reactions of the PMCPE at a molecular level are further confirmed in this quantum chemical simulation.

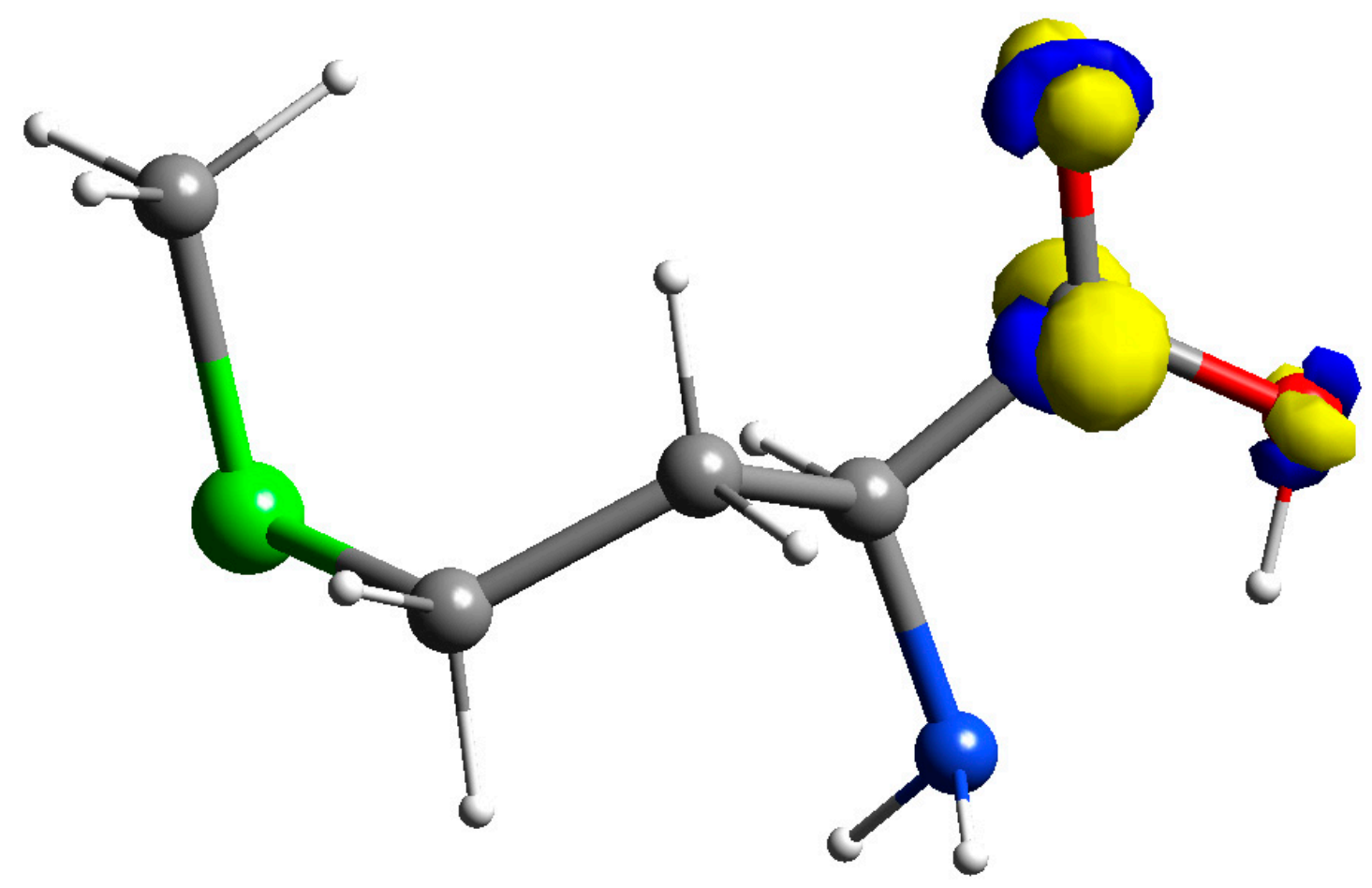

(a)

Figure 5. Cont. 


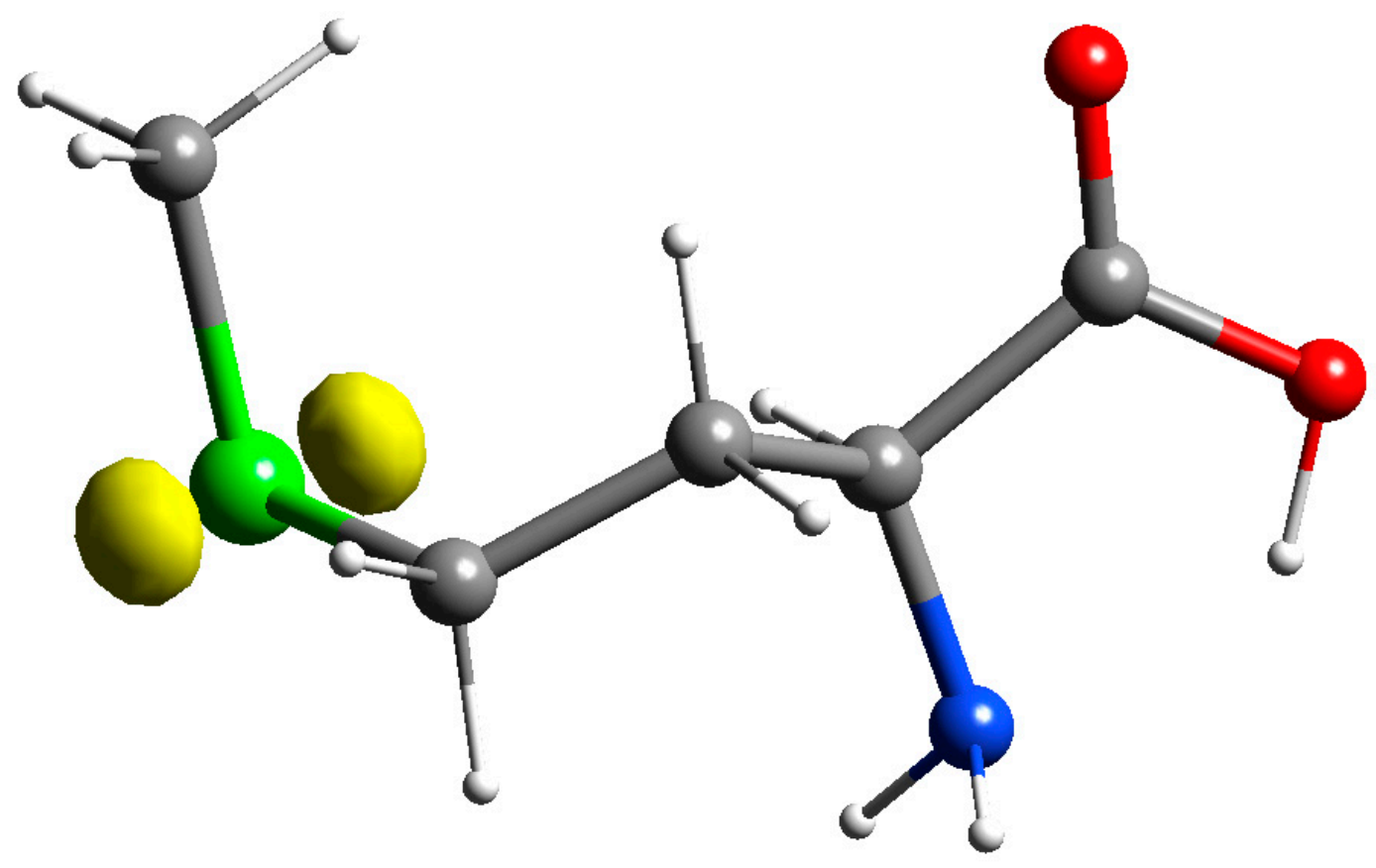

(b)

Figure 5. Fukui results of methionine: (a) Reduction sites of methionine $f^{+}(r)$ for PMCPE (isosurface value of 0.02); (b) Oxidation sites of methionine $f^{-}(r)$ for PMCPE (isosurface value of 0.02).

\subsection{Effect of Concentration of $D A$}

Cyclic voltammogramms of differently concentrated DA $\left(0.1\right.$ to $\left.1.9 \times 10^{-4} \mathrm{M}\right)$ are shown in Figure 6a. The anodic peak currents of DA have been found to increase linearly with the concentration of DA according to Figure $6 \mathrm{~b}$. The current can be expressed by linear regression in terms of the DA concentration using the following equation: $\mathrm{I}=0.639 \mathrm{C}+2.292$, where $\mathrm{I}$ is the current in $\mu \mathrm{A}$, and $\mathrm{C}$ is the DA concentration in $10^{-4} \mathrm{M}$. Therefore, the proposed PMCPE electrode can be used to detect the different concentrations of DA. 


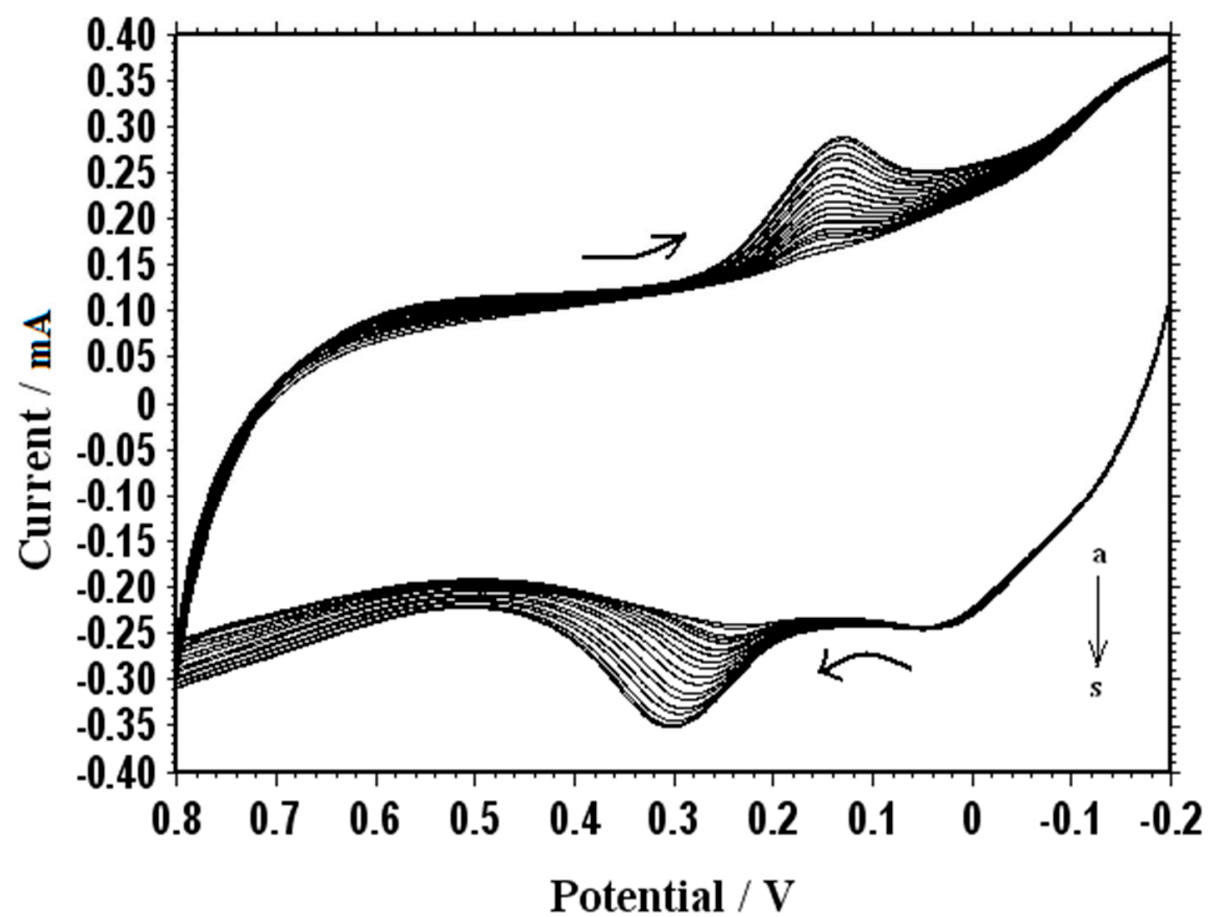

(a)

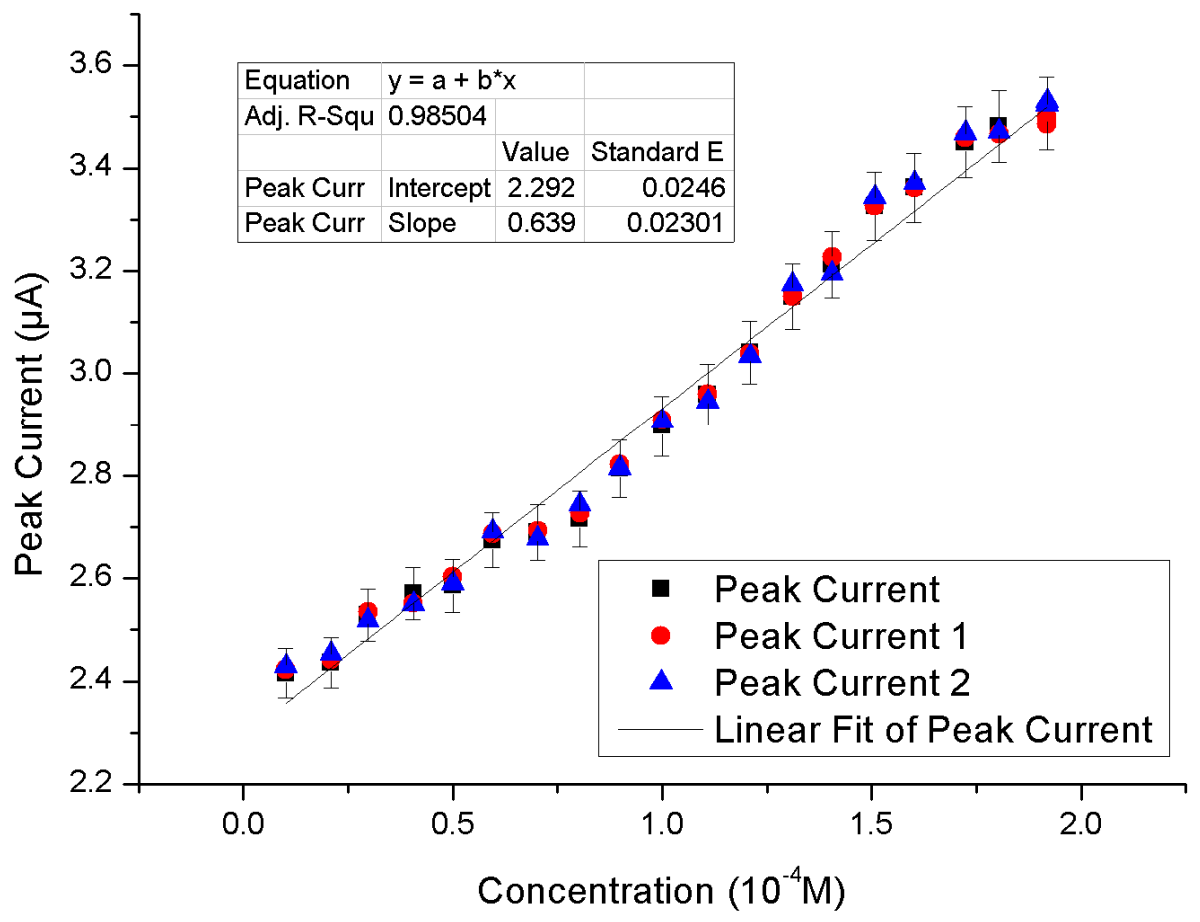

(b)

Figure 6. Effects of different concentrations of dopamine (DA): (a) Cyclic voltammograms of DA at different concentration (a-s; 0.1 to $1.9 \times 10^{-4} \mathrm{M}$ ) in $0.1 \mathrm{M}$ PBS ( $\mathrm{pH} 7.0$ ): Scan rate $100 \mathrm{mV} \cdot \mathrm{s}^{-1}$; (b) Effect of different concentrations of DA on the oxidation peak current at the PMCPE. 


\subsection{Effect of $p H$ on the Oxidation of $D A$}

The effect of $\mathrm{pH}$ on the electrochemical response of the PMCPE towards the determination of DA has been studied. Figure 7 shows the variation in peak potential of DA as a function of the change in $\mathrm{pH}$ of the electrolyte. As $\mathrm{pH}$ increases, the peak potential difference $\Delta \mathrm{Ep}$ decreases. The slope of the $\mathrm{pH}$ value was found to be $0.58 \mathrm{mV}$, suggesting that the proportion of the electron and proton involved in the reaction is 1:1 [28]. Since DA oxidation is a two-electron process, the number of protons involved in the oxidation process is also expected to be two. The peak potential difference can be expressed by linear regression, in terms of the $\mathrm{pH}$ value, using the following equation: $\Delta \mathrm{Ep}=-14.71 \mathrm{p}+168.64$, where $\Delta \mathrm{Ep}$ is the peak potential difference in $\mathrm{mV}$ and $\mathrm{p}$ is the $\mathrm{pH}$ value.

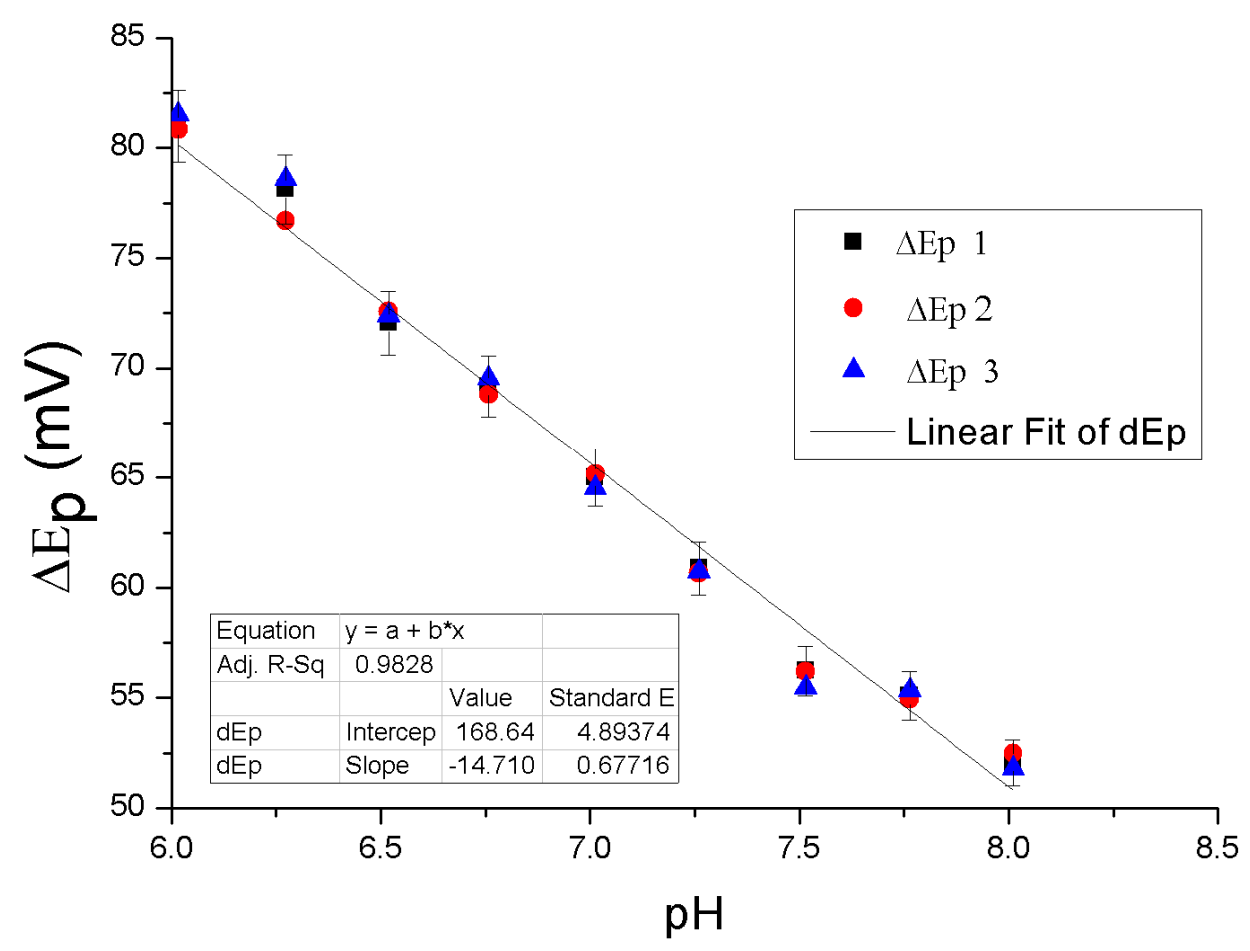

Figure 7. Effect of $\mathrm{pH}$ on the oxidation peak potential of $1 \times 10^{-4} \mathrm{M}$ DA at the PMCPE.

\subsection{Oxidation of Uric Acid}

The irreversible oxidation voltammogram of $\mathrm{UA}$ in $\mathrm{pH}=7.0$ at a BCPE occurs at $0.36 \mathrm{~V}$, with respect to the saturated calomel electrode, according to Curve a of Figure 8. According to Curve $b$ of Figure 8, when the PMCPE was placed into a blank buffer solution, a basis of redox peaks, attributing to oxidation and reduction of methionine, occurred. According to Curve c of Figure 8, the redox reaction occurs at approximately $0.41 \mathrm{~V}$, with a significant increase in current density when $1 \mathrm{mM} \mathrm{UA}$ was added to the $0.1 \mathrm{M}$ PBS solution. 


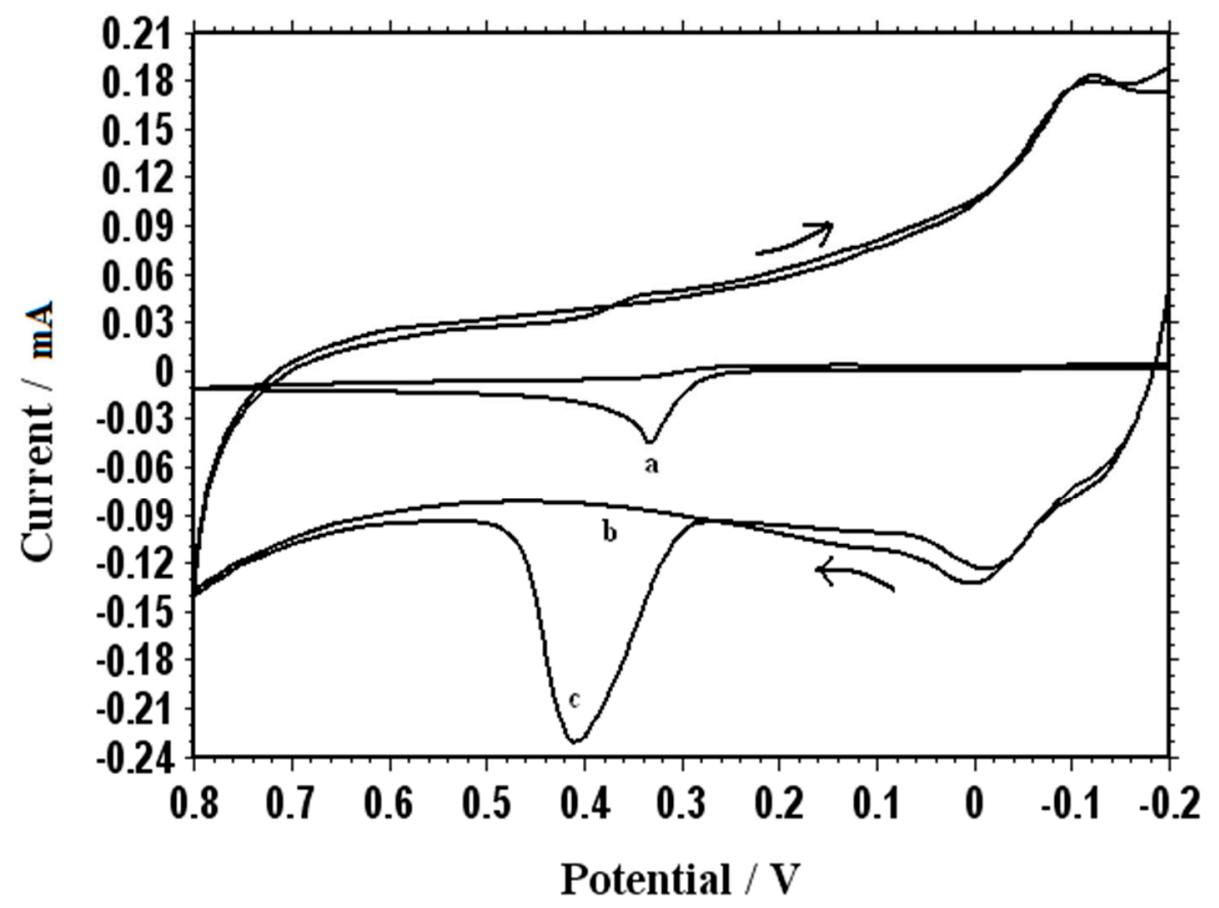

Figure 8. Cyclic voltammogram of the BCPE in $1 \mathrm{mM}$ uric acid (UA) is shown in Curve a. Curves b and $\mathrm{c}$ respectively show the cyclic voltammograms of the PMCPE in a blank buffer solution and in 1 mM UA (curve c) at $100 \mathrm{mV} \cdot \mathrm{s}^{-1}$ in $0.1 \mathrm{M}$ PBS (pH 7.0).

Figure 9a shows the cyclic voltammograms of $1 \mathrm{mM}$ uric acid on poly(methionine)/CPE at different scan rates. When the scan rate was incremented from $70 \mathrm{mV} \cdot \mathrm{s}^{-1}$ to $150 \mathrm{mV} \cdot \mathrm{s}^{-1}$, the peak currents also increased accordingly. The relationship of the anodic peak current with the scan rate was constructed and is illustrated in Figure 9b. Figure $9 b$ further confirms the fact that the electron transfer reaction was an adsorption-controlled process. According to Figure $9 \mathrm{~b}$, the current can be linearly regressed in terms of the scan rates using the following equation: $\mathrm{I}=0.0163 \mathrm{v}+0.7513$, where $\mathrm{I}$ is the current in $\mu \mathrm{A}$ and $\mathrm{v}$ is the scan rate in $\mathrm{mV} \cdot \mathrm{s}^{-1}$.

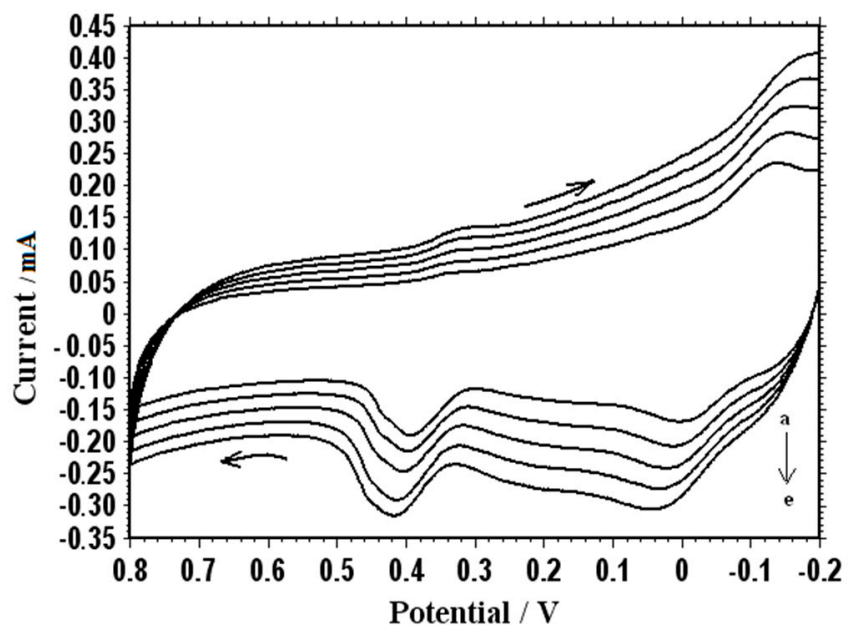

(a)

Figure 9. Cont. 


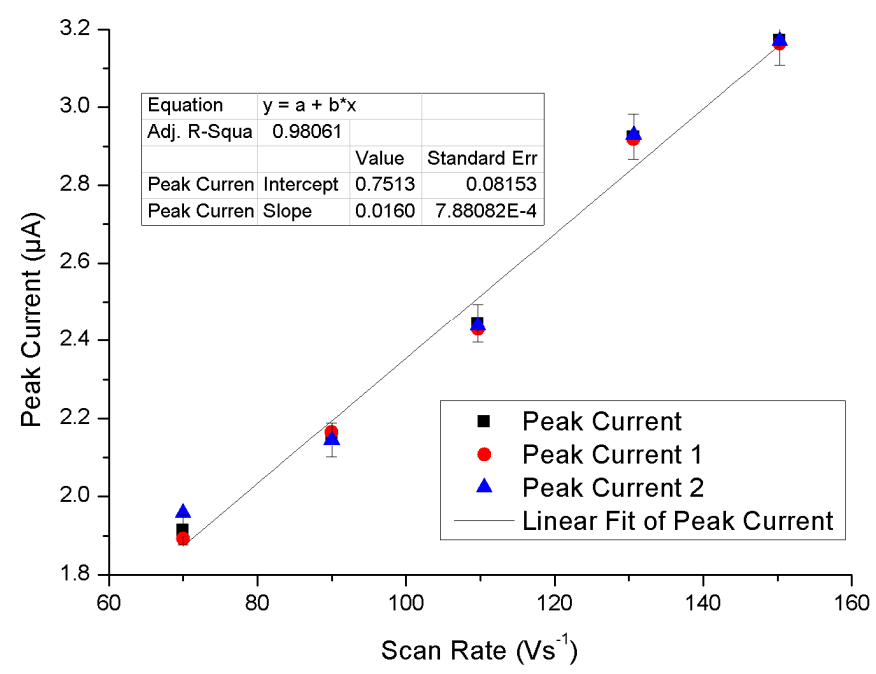

(b)

Figure 9. (a) Cyclic voltammogram of $1 \times 10^{-4} \mathrm{M}$ UA at different scan rates (70, 90, 110, 130, and 150 $\mathrm{mV} \cdot \mathrm{s}^{-1}$ ) in $0.1 \mathrm{M}$ PBS ( $\mathrm{pH} 7.0$ ); (b) Effect of different scan rates on the oxidation peak current of $1 \times$ $10^{-4} \mathrm{M}$ UA at the PMCPE.

\subsection{Simultaneous Determination of $D A$ and $U A$}

As shown in Figure 10, both DA and UA exhibit highly selective and sensitive electrochemical responses at the PMCPE. This performance is due to the electrostatic and hydrophobic interaction of DA and UA with methionine polymer at the PMCPE. In another experiment, the redox reactions of the DA and UA mixtures were studied. It can be observed from the solid line that the voltammetric responses of DA and UA almost overlap with each other when the BCPE was used and immersed in a phosphate-buffered solution at $\mathrm{pH}=7.0$. As the dotted line shows, however, two well-defined oxidation peaks (a dopamine oxidation peak around $0.25 \mathrm{~V}$ and an uric acid peak around $0.43 \mathrm{~V}$ ) with different currents were noticeably observed. The lowest concentrations for DA and UA were respectively $2 \times 10^{-8} \mathrm{~mol} / \mathrm{L}$ and $5 \times 10^{-8} \mathrm{~mol} / \mathrm{L}$.

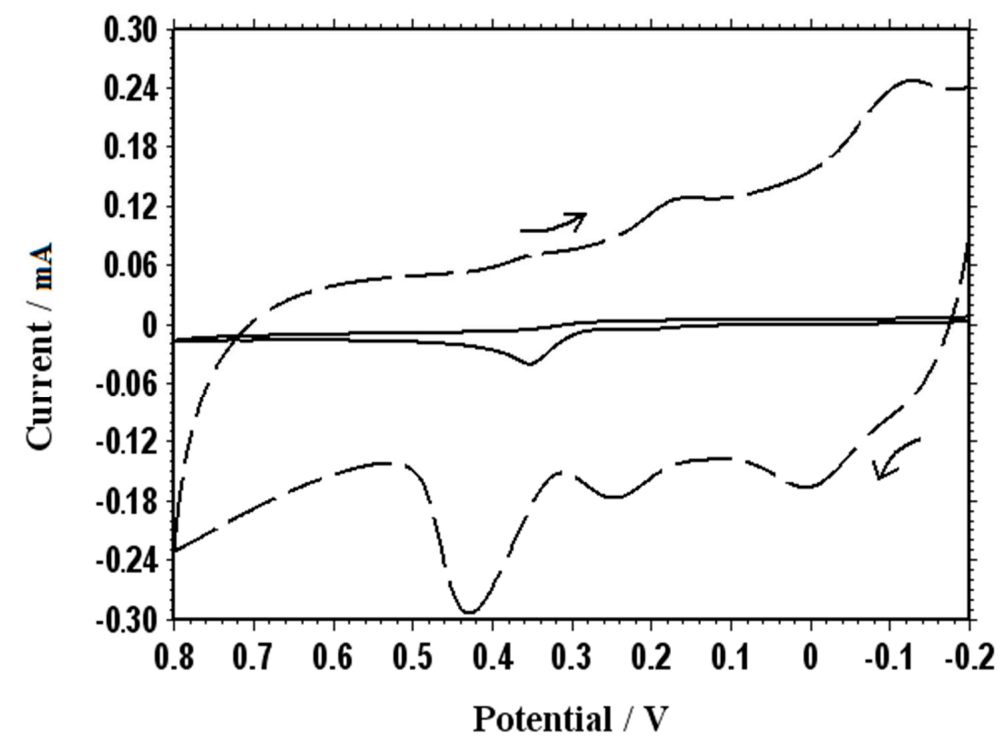

Figure 10. The cyclic voltammogram for simultaneous determination of $1 \times 10^{-4} \mathrm{M} \mathrm{DA}$ and $1 \times 10^{-3}$ $\mathrm{M}$ uric acid (UA) in 0.1 M PBS (pH 7.0) at a bare electrode (solid line) and a PMCPE (dashed line). Scan rate: $100 \mathrm{mV} \cdot \mathrm{s}^{-1}$. 


\section{Discussions}

The results of our Frontier simulation was in complete agreement with the published one [46]. Neither polymethionine nor carbon is toxic to human bodies. With some modification, a PMCPE can be easily implemented in micro-needles for in-vivo determination of UA and DA. At the time of this writing, many approaches for the simultaneous determination of UA and DA have been adopted (See Table 1). However, most of the published approaches involve the use of chemicals with unknown toxicity that renders in-vivo diagnosis difficult, if not impossible. Some of the known methods have been proven to be non-toxic, but the electric current involved in the analysis is too small to distinguish the UA or DA levels.

Table 1. Previously published approaches for simultaneous determination of UA and DA.

\begin{tabular}{ccc}
\hline Method & $\begin{array}{c}\text { Chemical(s)/Chemical } \\
\text { Modifier(s) Involved }\end{array}$ & Reference(s) \\
\hline 1 & Zinc Hexacyanoferrate Clay & {$[46]$} \\
\hline 2 & Ribonucleic acid (RNA) & {$[47]$} \\
\hline 3 & Poly(l-lysine)/Graphene Oxide & {$[48]$} \\
\hline 4 & $\beta$-Cyclodextrin & {$[49]$} \\
\hline 5 & Exfoliated Graphite Electrodes & {$[50]$} \\
\hline 6 & $\begin{array}{c}\text { Silver nanoparticle-decorated } \\
\text { reduced graphene oxide } \\
\text { composite }\end{array}$ & {$[51]$} \\
\hline 7 & Polyadenine & {$[52]$} \\
\hline
\end{tabular}

In this work, many PMCPEs have been fabricated to examine the repeatability of our measurements. Our repeated measurements on dopamine and uric acid using the fabricated PMCPEs have consistently yielded negligible standard derivations. This finding reinforces the fact that the electrochemical sites remain the same.

\section{Conclusions}

In the present study, a poly(methionine) modified carbon paste electrode (PMCPE) was used for the simultaneous determination of DA and UA in a phosphate-buffered solution at pH 7.0. The PMCPE is carbon paste electrode with a layer of poly(methionine) polymerized on the surface. In repeated a cyclic scan of a voltammogram, the modified electrode consistently yields two noticeably different and stable potentials of DA and UA, over a long period, with a low detection limit. According to the electrostatic electron maps, as well as the results of quantum chemical simulation using the Fukui equation, the sulfur atom of the poly(methionine) is responsible for the oxidation of PMCPE, whilst the carboxylic acid group of the poly(methionine) is responsible for the reduction of PMCPE. The electrocatalytic activity of poly(methionine) improves the reversibility of the cyclic voltammetric analysis and complete resolution of the anodic waves of the DA and UA. The theoretical and experimental approaches of this work point to the feasibility of realistic application of biocompatible electrodes in an in-vivo investigation of clinical interest.

Author Contributions: B.N.C. and B.E.K.S. designed and set up the experiments, G.K.J. performed computational calculations, K.H. performed electrostatic potential computations. B.N.C., G.K.J., W.L., and L.W.Y.L. wrote the manuscript. All authors have contributed to revising the paper.

Funding: This research received no external funding.

Conflicts of Interest: There are no conflicts to declare. 


\section{References}

1. Sochr, J.; Švorc, L'.; Rievaj, M.; Bustin, D. Electrochemical determination of adrenaline in human urine using a boron-doped diamond film electrode. Diam. Relat. Mater. 2014, 43, 5-11. [CrossRef]

2. Jayaprakash, G.K.; Swamy, B.E.K.; Chandrashekar, B.N.; Flores-Moreno, R. Theoretical and cyclic voltammetric studies on electrocatalysis of benzethonium chloride at carbon paste electrode for detection of dopamine in presence of ascorbic acid. J. Mol. Liq. 2017, 240, 395-401. [CrossRef]

3. Chandrashekar, B.N.; Swamy, B.K.; Gururaj, K.; Cheng, C. Simultaneous determination of epinephrine, ascorbic acid and folic acid using TX-100 modified carbon paste electrode: A cyclic voltammetric study. J. Mol. Liq. 2017, 231, 379-385. [CrossRef]

4. Damier, P.; Hirsch, E.C.; Agid, Y.; Graybiel, A.M. The substantia nigra of the human brain: II. Patterns of loss of dopamine-containing neurons in Parkinson's disease. Brain 1999, 122, 1437-1448. [CrossRef] [PubMed]

5. Zheng, J.; Yang, Y.; Tian, S.; Chen, J.; Wilson, F.A.; Ma, Y. The dynamics of hippocampal sensory gating during the development of morphine dependence and withdrawal in rats. Neurosci. Lett. 2005, 382, 164-168. [CrossRef]

6. Hashitani, T.; Mizukawa, K.; Kumazaki, M.; Nishino, H. Dopamine metabolism in the striatum of hemiparkinsonian model rats with dopaminergic grafts. Neurosci. Res. 1998, 30, 43-52. [CrossRef]

7. Sochr, J.; Cinková, K.; Švorc, L'.; Vojs, M.; Michniak, P.; Marton, M. Sensitive electrochemical determination of amlodipine in pharmaceutical tablets and human urine using a boron-doped diamond electrode. $J$. Electroanal. Chem. 2014, 728, 86-93.

8. Cinková, K.; Kianičková, K.; Stanković, D.M.; Vojs, M.; Marton, M.; Švorc, L'. The doping level of boron-doped diamond electrodes affects the voltammetric sensing of uric acid. Anal. Methods 2018, 10, 991-996. [CrossRef]

9. Baig, N.; Kawde, A.-N. A cost-effective disposable graphene-modified electrode decorated with alternating layers of $\mathrm{Au}$ NPs for the simultaneous detection of dopamine and uric acid in human urine. RSC Adv. 2016, 6, 80756-80765. [CrossRef]

10. Sathisha, T.V.; Swamy, B.E.K.; Chandrashekar, B.N.; Thomas, N.; Eswarappa, B. Selective determination of dopamine in presence of ascorbic acid and uric acid at hydroxy double salt/surfactant film modified carbon paste electrode. J. Electroanal. Chem. 2012, 674, 57-64. [CrossRef]

11. Rahman, M.M.; Ahmed, J.; Asiri, A.M. A glassy carbon electrode modified with $\gamma$-Ce2S3-decorated CNT nanocomposites for uric acid sensor development: a real sample analysis. RSC Adv. 2017, 7, 14649-14659. [CrossRef]

12. Chandrashekar, B.N.; Swamy, B.E.K.; Pandurangachar, M.; Sathisha, T.V.; Sherigara, B.S. Electropolymerisation of L-arginine at carbon paste electrode and its application to the detection of dopamine, ascorbic and uric acid. Colloids Surf., B 2011, 88, 413-418. [CrossRef] [PubMed]

13. Gilbert, O.; Swamy, B.E.K.; Chandra, U.; Sherigara, B.S. Simultaneous detection of dopamine and ascorbic acid using polyglycine modified carbon paste electrode: A cyclic voltammetric study. J. Electroanal. Chem. 2009, 636, 80-85. [CrossRef]

14. Wang, L.; Huang, P.; Bai, J.; Wang, H.; Zhang, L.; Zhao, Y. Simultaneous Electrochemical Determination of Phenol Isomers in Binary Mixtures at a Poly(phenylalanine) Modified Glassy Carbon Electrode. Int. J. Electrochem. Sci. 2006, 1, 403-413.

15. Gururaj, K.J.; Swamy, B.E.K. Electrochemical Synthesis of Titanium Nano Particles at Carbon Paste Electrodes and Its Applications as an Electrochemical Sensor for the Determination of Acetaminophen in Paracetamol Tablets. Soft Nanosci. Lett. 2013, 3, 20-22. [CrossRef]

16. Chitravathi, S.; Swamy, B.K.; Mamatha, G.; Chandrashekar, B. Electrocatalytic oxidation of tyrosine at poly(threonine)-film modified carbon paste electrode and its voltammetric determination in real samples. J. Mol. Liq. 2012, 172, 130-135. [CrossRef]

17. Chandrashekar, B.N.; Swamy, B.E.K.; Manjunatha, J.G.; Pandurangachar, M.; Sherigara, B.S. Simultaneous Investigation of Dopamine and Ascorbic Acid at Poly (Tryptophan) Modified Carbon Paste Electrode: A Cyclic Voltammetric Study. Anal. Bioanal. Chem. 2011, 3, 543-555.

18. Ma, W.; Sun, D.M. The electrochemical properties of dopamine, epinephrine and their simultaneous determination at a poly(L-methionine) modified electrode. Russ. J. Electrochem. 2007, 43, 1382-1389. [CrossRef] 
19. Zheng, X.; Guo, Y.; Zheng, J.; Zhou, X.; Li, Q.; Lin, R. Simultaneous determination of ascorbic acid, dopamine and uric acid using poly (l-leucine)/DNA composite film modified electrode. Sens. Actuator B Chem. 2015, 213, 188-194. [CrossRef]

20. Sun, D.; Ma, W.; Wu, Y. Preparation of Poly (L-isoleucine) Modified Electrode and Cyclic Voltammetric Determination of Dopamine. Chin. J. Appl. Chem. 2006, 23, 1214.

21. Jayaprakash, G.K.; Swamy, B.E.K.; Ramirez, H.N.G.; Ekanthappa, M.T.; Flores-Moreno, R. Quantum chemical and electrochemical studies of lysine modified carbon paste electrode surfaces for sensing dopamine. New J. Chem. 2018, 42, 4501-4506. [CrossRef]

22. Bergamini, M.F.; Santos, D.P.; Zanoni, M.V.B. Electrochemical behavior and voltammetric determination of pyrazinamide using a poly-histidine modified electrode. J. Electroanal. Chem. 2013, 690, 47-52. [CrossRef]

23. Ojani, R.; Alinezhad, A.; Abedi, Z. A highly sensitive electrochemical sensor for simultaneous detection of uric acid, xanthine and hypoxanthine based on poly(l-methionine) modified glassy carbon electrode. Sens. Actuator B Chem. 2013, 188, 621-630. [CrossRef]

24. Ojani, R.; Raoof, J.-B.; Maleki, A.A.; Safshekan, S. Simultaneous and sensitive detection of dopamine and uric acid using a poly(L-methionine)/gold nanoparticle-modified glassy carbon electrode. Chin. J. Catal. 2014, 35, 423-429. [CrossRef]

25. Chethana, B.K.; Naik, Y.A. Electrochemical oxidation and determination of ascorbic acid present in natural fruit juices using a methionine modified carbon paste electrode. Anal. Methods 2012, 4, 3754-3759. [CrossRef]

26. Wang, Y.; Ouyang, X.; Ding, Y.; Liu, B.; Xu, D.; Liao, L. An electrochemical sensor for determination of tryptophan in the presence of DA based on poly (L-methionine)/graphene modified electrode. RSC Adv. 2016, 6, 10662-10669. [CrossRef]

27. Cheemalapati, S.; Devadas, B.; Chen, S.-M. Highly sensitive and selective determination of pyrazinamide at poly-l-methionine/reduced graphene oxide modified electrode by differential pulse voltammetry in human blood plasma and urine samples. J. Colloid Interface Sci. 2014, 418, 132-139. [CrossRef] [PubMed]

28. Emami, M.; Shamsipur, M.; Saber, R. Design of poly-l-methionine-gold nanocomposit/multi-walled carbon nanotube modified glassy carbon electrode for determination of amlodipine in human biological fluids. $J$ Solid State Electrochem. 2014, 18, 985-992. [CrossRef]

29. Jayaprakash, G.K.; Swamy, B.E.K.; Casillas, N.; Flores-Moreno, R. Analytical Fukui and cyclic voltammetric studies on ferrocene modified carbon electrodes and effect of Triton X-100 by immobilization method. Electrochim. Acta 2017, 258, 1025-1034. [CrossRef]

30. Jayaprakash, G.K.; Flores-Moreno, R. Quantum chemical study of Triton X-100 modified graphene surface. Electrochim. Acta 2017, 248, 225-231. [CrossRef]

31. Jayaprakash, G.K.; Casillas, N.; Astudillo-Sánchez, P.D.; Flores-Moreno, R. Role of Defects on Regioselectivity of Nano Pristine Graphene. J. Phys. Chem. A 2016, 120, 9101-9108. [CrossRef] [PubMed]

32. Schaftenaar, G.; Noordik, J.H. Molden: A pre- and post-processing program for molecular and electronic structures. J. Comput. Aided Mol. Des. 2000, 14, 123-134. [CrossRef] [PubMed]

33. Frisch, M.J.; Trucks, G.W.; Schlegel, H.B.; Scuseria, G.E.; Robb, M.A.; Cheeseman, J.R.; Scalmani, G.; Barone, V.; Mennucci, B.; Petersson, G.A.; et al. Gaussian 09 Revision D.01; Gaussian Inc.: Wallingford, CT, USA, 2009.

34. Becke, A.D. Density-functional thermochemistry. III. The role of exact exchange. J. Chem. Phys. 1993, 98, 5648-5652. [CrossRef]

35. Lee, C.; Yang, W.; Parr, R.G. Development of the Colle-Salvetti correlation-energy formula into a functional of the electron density. Phys. Rev. B 1988, 37, 785-789. [CrossRef]

36. McLean, D.; Chandler, G.S. Contracted Gaussian basis sets for molecular calculations. I. Second row atoms, Z=11-18. J. Chem. Phys. 1980, 72, 5639-5648. [CrossRef]

37. Krishnan, R.; Binkley, J.S.; Seeger, R.; Pople, J.A. Self-consistent molecular orbital methods. XX. A basis set for correlated wave functions. J. Chem. Phys. 1980, 72, 650-654. [CrossRef]

38. Köster, A.M.; Geudtner, G.; Calaminici, P.; Casida, M.E.; Dominguez, V.D.; Flores-Moreno, R.; Gamboa, G.U.; Goursot, A.; Heine, T.; Ipatov, A.; et al. Salahub and deMon Developers, deMon2k; Version 3; The deMon Developers, Cinvestav: Mexico City, Mexico, 2011.

39. Flores-Moreno, R.; Pineda-Urbina, K.; Gomez-Sandoval, Z. Sinapsis, Version XII-V; Sinapsis Developers: Guadalajara, Mexico, 2012.

40. Torriero, A.A. Electrochemistry in Ionic Liquids; Springer: Cham, Switzerland, 2015. 
41. Parr, R.G.; Yang, W. Density functional approach to the frontier-electron theory of chemical reactivity. J. Am. Chem. Soc. 1984, 106, 4049-4050. [CrossRef]

42. Flores-Moreno, R. Symmetry Conservation in Fukui Functions. J. Chem. Theory Comput. 2010, 6, 48-54. [CrossRef] [PubMed]

43. Flores-Moreno, R.; Melin, J.; Ortiz, J.V.; Merino, G. Efficient evaluation of analytic Fukui functions. J. Chem. Phys. 2008, 129, 224105. [CrossRef]

44. Jayaprakash, G.K.; Flores-Moreno, R. Regioselectivity in hexagonal boron nitride co-doped graphene. New J. Chem. 2018, 42, 18913-18918. [CrossRef]

45. Zor, S.; Kandemirli, F.; Bingul, M. Inhibition Effects of Methionine and Tyrosine on Corrosion of Iron in $\mathrm{HCl}$ Solution: Electrochemical, FTIR, and Quantum-Chemical Study. Prot. Met. Phys. Chem. Surf. 2009, 45, 46-53. [CrossRef]

46. Kemmegn-Mbouguen, J.C.; Angnes, L.; Mouafo-Tchinda, E.; Ngameni, E. Simultaneous quantification of dopamine, acetaminophen and tyrosine at carbon paste electrodes modified with porphyrin and clay. Electroanalysis 2015, 27. [CrossRef]

47. Kang, G.; Lin, X. RNA Modified Electrodes for Simultaneous Determination of Dopamine and Uric Acid in the Presence of High Amounts of Ascorbic Acid. Electroanalysis 2006, 24. [CrossRef]

48. Zhang, Y.; Lei, W.; Xu, Y.; Xia, X.; Hao, Q. Simultaneous Detection of Dopamine and Uric Acid Using a Poly(l-lysine)/Graphene Oxide Modified Electrode. Nanomaterials 2016, 6, 178. [CrossRef] [PubMed]

49. Gong, W.; Dou, Z.; Cui, L.; Liu, D.; He, X. Electrocatalytic oxidation and simultaneous determination of uric acid, xanthine, hypoxanthine and dopamine based on $\beta$-cyclodextrin modified glassy carbon electrode. Chem. Res. Chin. Univ. 2012, 28, 1047-1053.

50. Ramesh, P.; Sampath, S. Selective Determination of Uric Acid in Presence of Ascorbic Acid and Dopamine at Neutral pH Using Exfoliated Graphite Electrodes. Electroanalysis 2004, 16. [CrossRef]

51. Kaur, B.; Pandiyan, T.; Satpati, B.; Srivastava, R. Simultaneous and sensitive determination of ascorbic acid, dopamine, uric acid, and tryptophan with silver nanoparticles-decorated reduced graphene oxide modified electrode. Colloids Surf. B Biointerfaces 2013, 111, 97-106. [CrossRef]

52. Li, H.; Wang, X.; Wang, Z. Simultaneous Determination of Dopamine, Uric Acid and Guanine at Polyadenine Film Modified Electrode. Anal. Sci. 2015, 31, 202-207. [CrossRef] 